\title{
The Fall of Titans: The Need to Reassess COX-2 Inhibitors
}

\author{
Steven Lin*, BMSc
}

\section{INTRODUCTION}

Two of the most popular arthritis medications came under great skepticism from the medical and scientific community in 2004. Long term clinical trials for both rofecoxib and celecoxib, also known as Vioxx and Celebrex, respectively, were stopped short by the Food and Drug Administration (FDA) due to increased cardiovascular risks to its subjects. The news came after five years of their use by the general public.

In 1999, an estimated 4 million Canadians and their doctors eagerly awaited the public launch of a revolutionary class of drugs: cyclooxygenase-2 (COX2 ) inhibitors (1). These drugs were part of a new class of non-steroidal anti-inflammatory drugs (NSAIDs) that offered a welcomed alternative to the traditional nonselective NSAIDs that were already on the market. The main effects of COX-2 inhibitors were to reduce inflammation and to provide pain relief for osteoarthritis and rheumatoid arthritis patients without the unpopular gastrointestinal (GI) complications of acetylsalicylic acid (ASA) and other traditional NSAIDs. Pharmaceutical companies aggressively marketed these "miracle" drugs to doctors and patients --and it worked.

In the first three months of Pfizer Inc.'s public release of celecoxib, Canadian pharmacies filled more than 428,400 prescriptions worth $\$ 20,736,000$ in sales (2). Celecoxib became the fastest selling consumer product, breaking the record of the widely-used sildenafil, better known as Viagra, which also happened to be a Pfizer product, of $\$ 13,306,000$ in 1998 (2). Only six months later, Merck \& Co. Inc. grabbed their part of the pie with their launch of their COX-2 selective inhibitor, rofecoxib. Rofecoxib was no ordinary copycat. It

\footnotetext{
* To whom correspondence should be addressed: Steven Lin, McGill Journal of Medicine, 3655 Promenade Sir William Osler, Montreal, QC, Canada, H3G 1 Y6

Email: steven.lin@mail.mcgill.ca
}

quickly became more popular than celecoxib and in 2003, rofecoxib was the 10th most prescribed medication in Canada (3). It became exceedingly common for an arthritis patient to walk out of a clinic with a COX-2 inhibitor prescription.

The popularity of these drugs was not at all surprising. Arthritic pain was and continues to be an important issue to many Canadians. Health Canada reported that nearly 4 million Canadians suffered from a form of arthritis, representing $16 \%$ of the population in 2000 (1). Arthritis was the second and third most common chronic condition reported by women and men, respectively. Although arthritis is commonly thought of as a disease of the elderly, nearly $60 \%$ of people that reported having arthritis were under the age of 65 (1). By 2026, Health Canada estimates the prevalence of arthritis to be $20.6 \%$, or $6,360,000$ million Canadians.

\section{COX AND COX INHIBITORS}

ASA and other NSAIDs are used primarily for their anti-inflammatory and analgesic effects through the inhibition of arachidonic acid hydrolysis by cyclooxygenase (COX). This leads to decreased production of prostaglandins and thromboxanes, collectively known as prostanoids, which are the endproducts of the COX pathway. These various endproducts perform a myriad of physiological functions ranging from constricting or dilating blood vessels, stimulating or inhibiting platelet aggregation, to causing pain sensation.

There are currently two defined COX genes: COX-1 and -2 . COX-1 and COX-2 are believed to subserve different physiological functions due to their different expression patterns. COX-1 is considered a "housekeeping" gene that is constitutively expressed in most tissues. However, this may be an oversimplification because COX-1 expression can be regulated in T-cell 
development and altered in disease states such as atherosclerosis. COX-1 has important homeostatic functions, which include maintaining gastric mucosal integrity and mediating normal platelet function. In contrast, COX-2 expression is low and highly restricted under basal conditions. However, during inflammatory responses, COX-2 expression is dramatically upregulated. Its parallel expression with inflammation increases with inflammatory mediators such as interleukin-1 (IL-1) and tumour necrosis factor- $\alpha$ (TNF- $\alpha$ ), and decreases with glucocorticoids.

Although structurally similar to COX-1, COX-2 has small yet important differences. COX-2 has a valine substitution for isoleucine at position 523 (4). The smaller valine amino acid leaves a gap in the wall of the enzyme, giving rise to a "side pocket", which is the binding site of many selective inhibitors, including rofecoxib and celecoxib $(4,5)$. When isoleucine was substituted with valine in the COX-1 enzyme, it was also inhibited by COX-2 selective inhibitors (6).

ASA and other traditional NSAIDs effectively decrease inflammation and reduce pain by nonselectively inactivating both COX enzymes. ASA irreversibly acetylates a specific serine residue on COX, thereby inhibiting its function. On the other hand, the traditional NSAIDs include both reversible and irreversible competitive inhibitors for the binding site of arachidonic acid. Interestingly, splice variants of both these enzymes exist. A splice variant of COX-1, sometimes referred to as $\mathrm{COX}-3$, is thought to be the active target of another analgesic, acetaminophen (7). Although patients receive the anti-inflammatory and analgesic effects with the inhibition of COX-2 using traditional therapies, some patients endure the undesirable side effects from the inhibition of COX-1, namely GI irritation, erosion, ulcer and even haemorrhaging (8). Intuitively, COX-2 inhibitors would achieve the desired effects of traditional medications without their side effects. This indeed was the outcome of many of the first trials published.

\section{ROFECOXIB}

In the Merck-sponsored randomized, double-blinded, stratified Vioxx Gastrointestinal Outcomes Research (VIGOR) trial, 8076 patients suffering from rheumatoid arthritis participated in determining the incidence of GI complications between rofecoxib and naproxen, a nonselective NSAID (9). The incidence of upper GI events such as perforations, obstructions, bleeding and/or ulcers, were significantly decreased in patients receiving rofecoxib treatment as compared to those using naproxen. This brought about wide acceptance of rofecoxib by many physicians and the general public. Luckily, some skeptics remained.
As clinicians and scientists sifted through the data from the VIGOR trial, questions were raised and skepticism grew. It was realized that only particular data were published for public reading, while other data were left out. Cardiovascular event data were later submitted to and reviewed by the FDA. The FDA Data and Safety Monitoring Board (DSMB) recommended a blinded adjudication of cardiovascular events of rofecoxib versus naproxen. A total of 98 cases $(65 / 4047$ from the rofecoxib group, 33/4029 from the naproxen group) were adjudicated for adverse events. There were 46 cases (in 45 people) in the rofecoxib group compared to 20 in the naproxen group to have confirmed serious adverse thrombotic cardiovascular events, such as myocardial infarctions (MI), unstable angina, cardiac thrombi, resuscitated cardiac arrests, sudden or unexplained deaths, ischemic strokes, and transient ischemic attacks. The cumulative incidence of developing thrombotic events was significantly higher with a relative risk (RR) of 2.38 (95\% CI, (1.39-4.00), $\mathrm{P}<.001)$ in the rofecoxib group $(10,11)$.

In addition, a subgroup analysis was performed on patients with a past medical history of stroke, transient ischemic attack, MI, unstable angina, angina pectoris, coronary artery bypass grafting, or percutaneous coronary interventions, who were classified as aspirinindicated, versus those whom aspirin was not indicated. The RR of developing thrombotic events between the rofecoxib group and the naproxen group was 4.89 (95\% CI, 1.41-16.88, P=.01) and 1.89 (95\% CI, 1.03-3.45, $\mathrm{P}=.04)$ in aspirin-indicated patients and aspirin not indicated patients, respectively. Rofecoxib clearly increased the risk of suffering cardiovascular events, especially in patients with a previous history of significant cardiovascular disease $(10,11)$.

Although the sponsors of the VIGOR trial attempted to explain the increased cardiovascular risk of rofecoxib compared to naproxen was primarily due to naproxen's anti-platelet cardioprotective effect (11), the DSMB nevertheless suggested the Vioxx label include a warning to consumers of the increased cardiovascular risks. Unfortunately for Merck, this would not be the end of its problems.

On September 30th, 2004, Merck voluntarily announced a worldwide withdrawal of rofecoxib after preliminary results from a clinical trial showed a significant overall increase in incidence by a factor of 3.9 of serious thromboembolic events such as MIs and strokes in patients receiving $25 \mathrm{mg} /$ day of rofecoxib compared to placebo (12). The planned 3-year clinical trial called APPROVe (Adenomatous Polyp Prevention of Vioxx) was forced to stop short by two months by the DSMB. The randomized, double-blinded study, which enrolled about 2600 patients at 100 sites, was evaluating 
the efficacy of rofecoxib in preventing the recurrence of colorectal polyps in patients with a past medical history of colorectal adenomas. After 18 months of treatment, patients receiving rofecoxib were 1.8 times more likely (attributable risk $=1.5 \%$ ) to suffer from MIs or strokes compared to those receiving placebo (13).

\section{CELECOXIB}

Since rofecoxib's withdrawal from the market, Pfizer's celecoxib, the next most commonly prescribed COX-2 inhibitor, received major attention as to its safety. Canada's Adverse Drug Reaction Information System (CADRIS) database maintained by Health Canada showed nearly the same number of suspected adverse reaction reports for both celecoxib and rofecoxib (14). Although these are unproven reports from patients, consumers, doctors, pharmacists, and/or other health professionals, Health Canada uses this database as an early detection system for possible safety concerns with medications.

Similar to Merck, Pfizer sponsored a large scale clinical trial to determine the efficacy of celecoxib. The Celecoxib Long Term Arthritis Safety Study (CLASS) trial consisted of two separate studies comparing the effects of celecoxib to ibuprofen (400mg bid) and diclofenac (75mg bid). In the original report, celecoxib appeared to have a decreased risk in developing GI side effects such as bleeding, perforation, and obstruction, and no increased cardiovascular risk (15). But it was soon realized that data were again withheld from the public. The study lasted 13 months but only 6 months of follow-up data were published. Analysis of the subsequent data revealed that celecoxib had no statistically significant difference in the overall incidence of the predefined GI end points $(0.8 \%$ in the celecoxib group versus $1.5 \%$ in either NSAID group, $\mathrm{P}=0.09) \quad(16,17)$. Celecoxib's lack of long-term gastroprotective effects may be explained by its low selectivity ratio $(\mathrm{COX}-2 / \mathrm{COX}-1)$ as compared to rofecoxib (8).

On December 17th, 2004, the National Cancer Institute announced its premature cessation of a celecoxib trial known as Adenoma Prevention with Celecoxib (APC) due to a significant increase in cardiovascular risk. The APC trial enrolled 2026 patients, who were randomized into 1 of 3 groups: placebo, celecoxib 200mg bid, or celecoxib 400mg bid. The groups were followed for an average of 33 months of a planned 60 months. There was a significant increase in the number of cardiovascular events, which included cardiovascular deaths, MIs, and strokes, in both celecoxib groups. A dose-response effect was observed between the celecoxib and placebo groups. There were 2.5-fold and 3.4-fold increases in cardiovascular risk in those taking daily doses of celecoxib 400mg and 800mg, respectively $(19,20)$.

\section{PROSTANOID BALANCE}

Rofecoxib, celecoxib and arguably other COX-2 inhibitors, are thought to increase the risk of adverse cardiovascular events due to the suppression of prostaglandin $\mathrm{h}_{2}\left(\mathrm{PGI}_{2}\right)$, also known as prostacyclin. $\mathrm{PGI}_{2}$ has been shown to be the predominate COX endproduct in the vascular endothelium where its functions include inhibition of platelet aggregation, inhibition of platelet and neutrophil adhesion, and dilation of bronchial and vascular smooth muscle. It was previously thought that $\mathrm{PGI}_{2}$ was mainly derived from $\mathrm{COX}-1$, but it was later shown that $\mathrm{PGI}_{2}$ is a COX-2 product (21). The cardiovascular effects of $\mathrm{PGI}_{2}$ contrast those of thromboxane $\mathrm{A}_{2}\left(\mathrm{TXA}_{2}\right)$, a major product of platelet COX-1. Whereas ASA and other traditional NSAIDs inhibit both COX enzymes and thus both $\mathrm{PGI}_{2}$ and $\mathrm{TXA}_{2}$ production, the selective COX-2 inhibitors do not appreciably inhibit $\mathrm{TXA}_{2}$ production.

It is believed by some groups that COX-2 may be induced by haemodynamic stress on endothelial cells in vivo as in vitro studies have shown (22). If so, the suppression of $\mathrm{PGI}_{2}$ formation by selective COX-2 inhibitors may predispose patients to thromboembolic events (12). This is especially important in patients with a history of cardiovascular disease. Depression of $\mathrm{PGI}_{2}$ formation by COX-2 inhibitors would increase their intrinsic risks of suffering clinical cardiovascular events (23).

\section{CONCLUSION}

Individual patient accounts claim improved analgesia with COX-2 selective inhibitors over traditional NSAIDs. However, the superiority of COX-2 inhibitors over traditional NSAIDs has not been clinically tested. In considering the anecdotal efficacy, higher cost, and proven cardiovascular risks, the public use of COX-2 inhibitors is controversial, to say the least. So where does this leave arthritis patients? As the hype of these miracle drugs turn to concern, should the public turn its back to all COX-2 inhibitors? The burden of proof rests with the pharmaceutical companies to prove the safety of their drugs. Although there are other pharmacological uses and risks of these drugs that are beyond the breadth of this review, there is a clear need to exercise prudence and caution to the use of COX-2 inhibitors. More research is required to determine the safety of all COX-2 inhibitors, including Pfizer's valdecoxib (Bextra) and its prodrug, parecoxib (Dynastat). Concerns over the safety of both valdecoxib and parecoxib have already risen. Two randomized, double-blinded, placebo-controlled 
clinical trials showed that both valdecoxib and parecoxib increased the risk of cardiovascular events by approximately 3-fold in patients after coronary artery bypass grafting $(24,25)$. On April 7 th, Pfizer withdrew valdecoxib from the market due to concerns over valdecoxib's associated increased risk of cardiovascular events and of serious skin reactions $(26,27)$.

The Merck and Pfizer cases have attracted much public attention and concern. Physicians and the general public are demanding answers and some are even seeking monetary compensation through classaction lawsuits. The onus is on pharmaceutical companies to produce the required research data on their drugs. Long term, randomized, double-blinded clinical trials provide the best evidence of a drug's potential use and more importantly, of its safety. Moreover, the FDA and Health Canada have the duty and responsibility to be more stringent on their approval of drugs for public use. This is a failing on both sides. Let us hope that these important lessons are welllearned.

\section{REFERENCES}

1. Health Canada. Statistics Canada microdata tape Canadian Community Health Survey, 2000. Available at: http://www.phac-aspc.gc.ca/publicat/ac/ac_3e.html. Accessibility verified April 17, 2005.

2. Intercontinental Medical Statistics Canada. 1999. Available at: http://www.imshealthcanada.com/htmen/4_2_1_15.htm. Accessibility verified April 17, 2005.

3. Intercontinental Medical Statistics Canada. 2003. Available at: http://www.imshealthcanada.com/htmen/1_0_12.htm. Accessibility verified April 17, 2005.

4. Luong C, Miller A, Barnett J, et al. The structure of human cyclooxygenase-2; conservation and flexibility of the NSAID binding site. Nat Struct Biol 3:927-33; 1996.

5. Hawkey CJ. COX-2 inhibitors. Lancet 353(9149):307-14; 1999.

6. Gierse JK, McDonald JJ, Hauser SD, et al. A single amino acid difference between cyclooxygenase-1 (COX-1) and -2 (COX-2) reverses the selectivity of COX-2 specific inhibitors. J Biol Chem 271:15810-4; 1996.

7. Chandrasekharan NV, Dai H, Roos KL, et al. COX-3, a cyclooxygenase-1 variant inhibited by acetaminophen and other analgesic/antipyretic drugs: cloning, structure, and expression. Proc Natl Acad Sci U S A 99(21):13926-31; 2002.

8. Henry D, Lim LL, Garcia Rodriguez LA, et al. Variability in risk of gastrointestinal complications with individual non-steroidal anti-inflammatory drugs: results of a collaborative metaanalysis. BMJ 312(7046): 1563-6; 1996.

9. Bombardier C, Laine L, Reicin A, et al. Comparison of upper gastrointestinal toxicity of rofecoxib and naproxen in patients with rheumatoid arthritis. N Engl J Med 343:1520-8; 2000.

10. Mukherjee D, Nissen SE, Topol EJ. Risk of cardiovascular events associated with selective COX-2 inhibitors. JAMA 286:954-9; 2001.
11. Food and Drug Administration Advisory Committee. Cardiovascular Safety Review of Rofecoxib. 2001. Available at: http://www.fda.gov/ohrms/dockets/ac/01/briefing/3677b2_06_c ardio.pdf. Accessibility verified April 17, 2005.

12. FitzGerald GA. Coxibs and Cardiovascular Disease. N Engl J Med 351:1709-11; 2004.

13. Sibbald B. Rofecoxib (Vioxx) voluntarily withdrawn from market. CMAJ 171(9):1027-8; 2004.

14. Canadian Broadcasting Corporation. 2004. Available at: http://www.cbc.ca/story/science/national/2004/11/04/vioxx_cel ebrex041.html. Accessibility verified April 17, 2005.

15. Silverstein FE, Faich G, Goldstein JL, et al. Gastrointestinal toxicity with celecoxib vs nonsteroidal anti-inflammatory drugs for osteoarthritis and rheumatoid arthritis: the CLASS study: A randomized controlled trial. Celecoxib Long-term Arthritis Safety Study. JAMA 284(10):1247-55; 2000.

16. Lu HL. Statistical Reviewer Briefing Document for the Advisory Committee. Available at: http://www.fda.gov/ ohrms/dockets/ac/01/briefing/3677b1_04_stats.doc. Accessibility verified April 17, 2005.

17. FitzGerald GA, Patrono C. The coxibs, selective inhibitors of cyclooxygenase-2. N Engl J Med 345(6):433-42; 2001.

18. Warner TD, Giuliano F, Vojnovic I, et al. Nonsteroid drug selectivities for cyclo-oxygenase-1 rather than cyclo-oxygenase2 are associated with human gastrointestinal toxicity: a full in vitro analysis. Proc Natl Acad Sci U S A 96:7563-8; 1999.

19. Couzin J. Clinical trials. Halt of Celebrex study threatens drug's future, other trials. Science 306(5705):2170; 2004.

20. Topol EJ. Arthritis medicines and cardiovascular events--"house of coxibs". JAMA 293(3):366-8; 2005.

21. Caughey GE, Cleland LG, Penglis PS, et al. Roles of cyclooxygenase (COX)-1 and COX-2 in prostanoid production by human endothelial cells: selective up-regulation of prostacyclin synthesis by COX-2. J Immunol 167(5):2831-8; 2001.

22. Dancu MB, Berardi DE, Vanden Heuvel JP, et al. Asynchronous shear stress and circumferential strain reduces endothelial NO synthase and cyclooxygenase-2 but induces endothelin-1 gene expression in endothelial cells. Arterioscler Thromb Vasc Biol 24(11):2088-94; 2004.

23. Warner TD, Vojnovic I, Giuliano F, et al. Cyclooxygenases 1, 2, and 3 and the production of prostaglandin I2: investigating the activities of acetaminophen and cyclooxygenase-2-selective inhibitors in rat tissues. J Pharmacol Exp Ther 310(2):642-7; 2004.

24. Ott E, Nussmeier NA, Duke PC, et al. Efficacy and safety of the cyclooxygenase 2 inhibitors parecoxib and valdecoxib in patients undergoing coronary artery bypass surgery. J Thorac Cardiovasc Surg 125:1481-92; 2003.

25. Nussmeier NA, Whelton AA, Brown MT, et al. Complications of the COX-2 inhibitors parecoxib and valdecoxib after cardiac surgery. N Engl J Med 352(11):1081-91; 2005.

26. Food and Drug Administration. Alert for Healthcare Professionals Valdecoxib (marketed as Bextra), 2005. Available at: http://www.fda.gov/cder/drug/InfoSheets/HCP/ valdecoxibHCP.htm. Accessibility verified April 17, 2005.

27. Sibbald B. Pfizer to withdraw valdecoxib (Bextra) at Health Canada's request. CMAJ 172(10):e1298; 2005.

Steven Lin is the MJM's ninth Editor-in-chief and is a medical student at McGill University. He received his B.M.Sc.(Hon.) in physiology from the University of Western Ontario. His research in cardiovascular disease has earned him scholarships from the Heart and Stroke Foundation and St. Michael's Hospital in Toronto, Canada. 